\title{
A Comparative Study on Methods of Connecting Large-Scale Offshore Wind Farms into Power Systems
}

\author{
Yuan-Kang $\mathrm{Wu}^{\mathrm{a}} *$, Ching-Yin Lee ${ }^{\mathrm{b}}$, Jian-Hong $\operatorname{Pan}^{\mathrm{c}}$ \\ ${ }^{a}$ National Chung-Cheng University, No.168 University Road, Minghsiung, Chaiyi 62102, Taiwan \\ ${ }^{b}$ Tungnan University, No.152, Sec. 3, Beishen Road, Shenkeng Dist., New Taipei City 222, Taiwan \\ ${ }^{c}$ Taiwan Power Company, No.242, Sec. 3, Roosevelt Rd., Zhongzheng District, Taipei City 100, Taiwan
}

\begin{abstract}
The paper uses PSS/E software to study connecting an offshore wind farm with 864 MW into the 2015 Taiwan power system. Major simulation works include: steady-state power flow, fault current computation, transient stability analysis and the impact analysis on critical fault clearing time. Three connection methods, i.e., single-point, separatepoint and multi-point connection, are proposed, in which the single-point connection is divided into two voltage levels $(161 \mathrm{kV}$ and $345 \mathrm{kV})$. During the steady-state operation, simulation results indicate that the $345 \mathrm{kV}$ single-point connection method demonstrates the best performance. In addition, the fault current from a wind farm is partially determined by its connection location. In terms of transient stability, when grid faults take place, the $161 \mathrm{kV}$ singlepoint connection method appears to report the smallest voltage drop as compared to other connection scenarios. Its amplitude of frequency disturbance, however, is the greatest of all connection scenarios. As for the analysis on critical fault clearing time, simulation results indicate that the critical fault clearing time in all connection cases is approximately two times greater than that required by the Taipower standard. Simulation results in this study can be expected to provide valuable guidelines for connecting offshore wind farms into the power systems in the future.
\end{abstract}

Keywords: Offshore wind farm, connection methods, steady-state power flow, fault current computation, transient stability, critical clearing time

\section{Introduction}

At present, the EU member states and other countries, such as China and U.S., are planning a significant expansion of the wind power capacity, especially offshore [1]. The reason for increasing offshore wind power is that wind speed offshore is potentially higher than onshore, which leads to a much higher power production. A $10 \%$ increase in wind speed results theoretically in a $30 \%$ increase in power production. Grid connection is a critical factor for successful large scale integration of offshore wind power. In [2], a comparative study between two different grid building strategies for offshore wind farms (302 GW installed wind capacity) in the North Sea is presented. These two strategies include the strategy based on radial wind farm connections to shore and point-to-point interconnections between countries, called radial grid, and the strategy based on the use of offshore nodes to build an HVDC offshore grid, called offshore grid. The analyzed results show that the offshore grid strategy is better than the radial one. This study clearly testifies to the importance of careful planning and design in the development of largescale offshore wind farms.

As countries around the world all strive to increase the penetration of renewable energy in power generation, power system safety, stability, and quality become a crucial issue. A large-scale wind farm brings a huge volume of power into the system so that existing lines may be overloaded, and even the capacity of equipment and facilities may fail to cope with the connection of wind farm into power system, thereby generating various problems [3]. Comprehensive study of wind farm location and connection

\footnotetext{
* Manuscript received July 10, 2012; revised August 18, 2012.

Corresponding author. Tel.: +886-5-2720411 ext. 33232; E-mail address: allenwu@ccu.edu.tw.
} 
methods is thus an issue of imperative importance. These connection methods can be evaluated by the system simulation analyses such as steady-state power flow, short-circuit current, and transient stability [4] after the wind farm is integrated into the system. Moreover, the safety capacity, unit dispatch strategies, and possible protection strategies of the wind farm when the system experiences grid faults are further major issues for in-depth analysis [5].

The study aims at evaluating the methods of connecting the Zhanghua Offshore Wind Farm in Taiwan (with a scheduled capacity of 864 MW) into the 2015 Taipower system. Three connection methods single-point connection, separate-point connection, and multiple-point connection - are examined, and issues related to steady-state flow and transient stability are analyzed so as to understand the impacts of connecting the wind farm into the power system and to provide relevant insights for future development of large-scale wind farms.

\section{Introduction to the Simulation System}

In the study, the single-, separate-, and multiple-point connection methods, along with different transmission voltage levels $(161 \mathrm{kV}$ and $345 \mathrm{kV})$, were evaluated for a large offshore wind farm planning in Taiwan. The $161 \mathrm{kV}$ single-point connection method is shown in Fig.1, where the voltage is transferred from $23.9 \mathrm{kV}$ to $161 \mathrm{kV}$ at an offshore substation and then connects into the Taiwan grid in a single point. For the separate-point connection method, the total capacity of the wind farm is equally divided into two independent parts with a capacity of $432 \mathrm{MW}$ each, and they are connected to the Taiwan grid at different bus, which is shown in Fig.2. The third connection method is shown in Fig.3, where the offshore wind farm is not separated into 2 or more parts but is interconnected into the Taiwan grid at 2 different onshore buses. The circuit topology of the fourth method, as shown in Fig.4, is identical to the single-point connection method but the voltage is transferred from $23.9 \mathrm{kV}$ to $345 \mathrm{kV}$ at an offshore substation.

In the study, the 864MW Zhanghua Offshore Wind Farm is scheduled for connection to the 2015 Taiwan power system. By 2015, the power system in Taiwan will no longer be characterized by the previously recognized "south- to-north" power transmission. Instead, the situation would be changed to various scenarios, including "south and north-to-central" or "north-to-central" transmission at off-peak hours and "central-to-north and south" transmission during peak hours. The status of power transmission in Taiwan would be affected by connection of new power sources (the $4^{\text {th }}$ nuclear power plant, stateowned and private wind farms, etc.) into the system and thus expected to undergo further changes in the future.

The study assumes that Type C DFIG (double-fed induction generator) wind turbines, a mainstream product in the market, are used in the offshore wind farm. This type of wind turbine is equipped with a rated real power of $3.6 \mathrm{MW}$, a cut-in wind speed of $3.5 \mathrm{~m} / \mathrm{s}$, a rated wind speed of $14 \mathrm{~m} / \mathrm{s}$, a cut-out wind speed of $27 \mathrm{~m} / \mathrm{s}$, and a rated voltage of $4.16 \mathrm{kV}$. Moreover, in steady-state situation, the wind turbine is capable of operating in two modes: power factor control and voltage control.

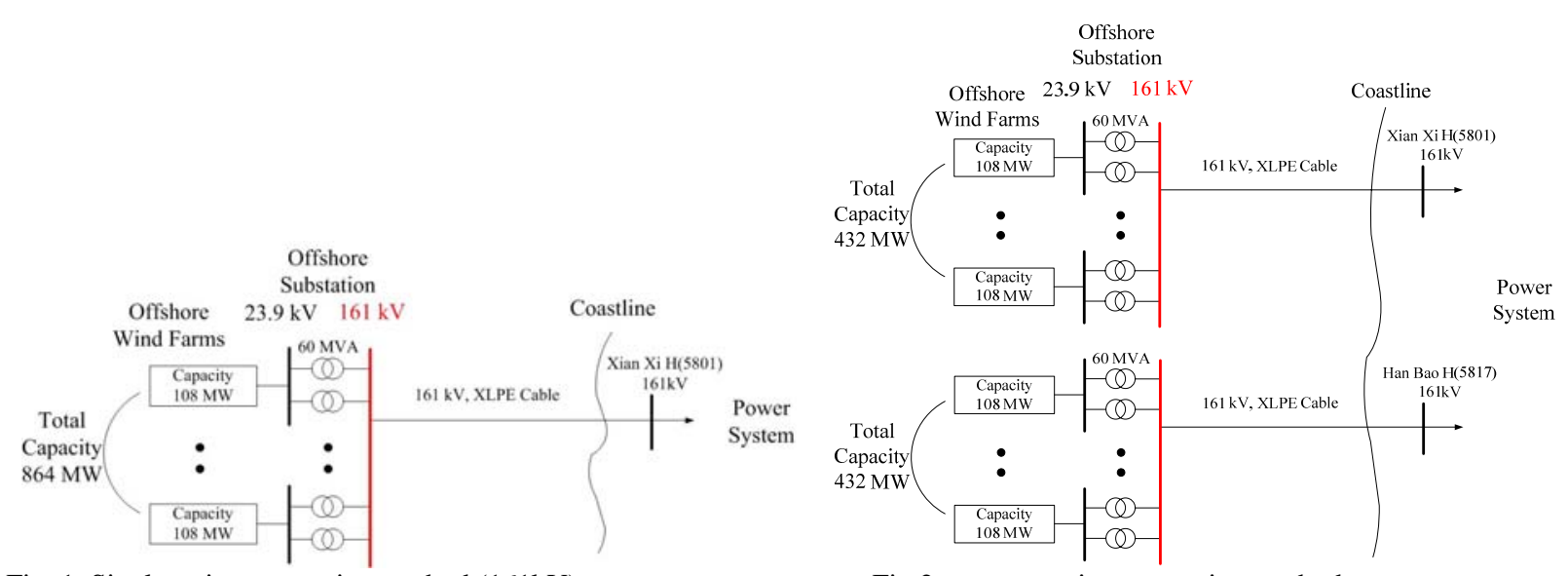

Fig. 1. Single-point connection method (161kV).
Fig.2 separate-point connection method. 


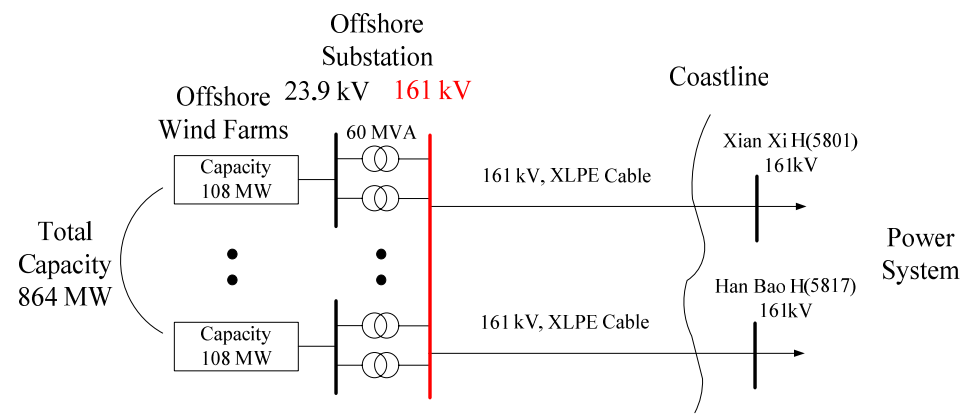

Fig. 3. Multiple-point connection method.

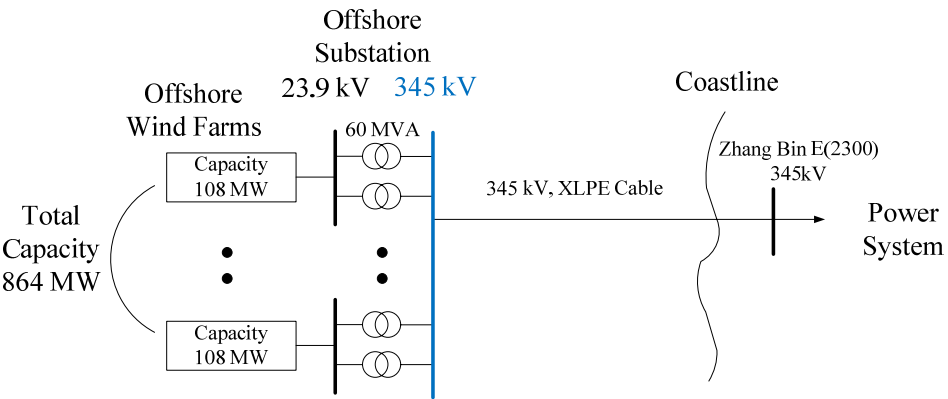

Fig.4. Single-point connection method (345kV).

\section{Protection Relay Settings for the Wind Turbines in This Study}

As wind power accounts for an increasing percentage, more and more attention has been directed to the impacts of large wind farms on the power system stability. Therefore, the United States and several European countries have revised regulations concerning the operation of wind turbines in the grid codes [6], such as setting more rigorous requirements for connection techniques, regulating the voltage and frequent range for the continuous operation of wind turbines, and demanding wind turbines to be equipped with low voltage ride through (LVRT) ability [7]. In setting the protection relays for the adopted wind turbines, this study has consulted Technical Rules of Renewable Energy Generation Connected to Taipower Transmission and Distribution Systems [8]. According to related regulations, wind turbines connected to a $25 \mathrm{kV}$ (or above) system needs to sustain the LVRT ability so as to keep the wind turbines in operation when the system occurs faults. Major technical rules in this study are illustrated by Figs.5-6. Fig.5 shows the LVRT curve in current Taiwan's grid code, and Fig.6 indicates the continuous operation range on frequency for the protection relay.

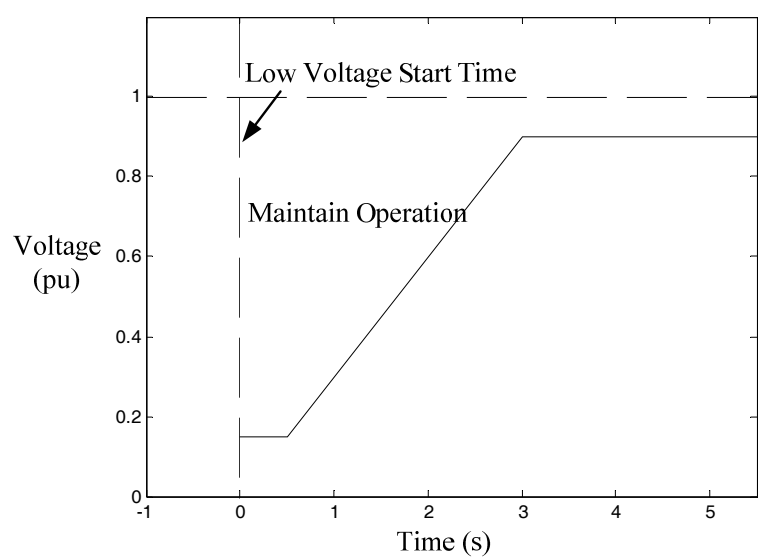

Fig. 5. LVRT requirement in Taiwan. 


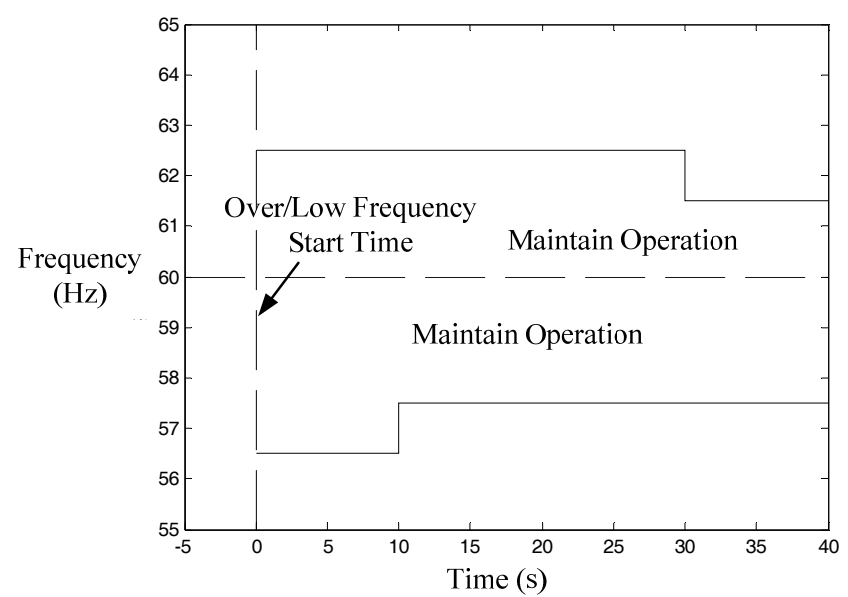

Fig.6. Continuous frequency operation range.

\section{Steady-State Analysis}

\subsection{Power flow analysis}

The section analyzes the power flow after the wind farm is connected to the Taipower system, assuming that the wind farm operates at the rated and fixed wind speed for full-load power generation. Under normal condition, when the transmission lines are overloaded after the connection of the wind farm into the power system, the number of transmission lines needs to be increased or the lines changed to sustain a higher rated capacity. Table 1 summarizes the simulation results for steady-state power flow: in the scenario of $345 \mathrm{kV}$ single-point connection, no transmission lines in the Zhang Bin extra high voltage area are overloaded, since the power generated by the wind farm flows into the power system directly from the $345 \mathrm{kV}$ lines, bypassing the $161 \mathrm{kV}$ lines in that area. By contrast, when $161 \mathrm{kV}$ lines are used to connect between wind farm and the grid, and the wind farm is operating for full-load power generation during peak hours, then overloading occurs in all three scenarios of $161 \mathrm{kV}$ connections. Two lines are overloaded based on the $161 \mathrm{kV}$ single-point connection method, while $161 \mathrm{kV}$ separate-point and 161 $\mathrm{kV}$ multi-point connection each has one line overloaded.

Table 1. Simulation results of steady-state power flow analysis at peak hours

\begin{tabular}{ll}
\hline \multicolumn{1}{c}{ Connection method } & \multicolumn{1}{c}{ Simulation Results } \\
\hline \multirow{2}{*}{$161 \mathrm{kV}$ Single-point Connection } & $\begin{array}{l}\text { 2 overloaded lines (the branch connecting Fusing H-5855 and Cao Gang bifurcation H- } \\
7710 \text { and the branch connecting Cao Gang bifurcation H-7710 and Zhang Bin H-2301). }\end{array}$ \\
\hline \multirow{2}{*}{$161 \mathrm{kV}$ Separate-point Connection } & $\begin{array}{l}1 \text { overloaded line (the branch connecting Fusing H-5855 and Cao Gang bifurcation H- } \\
7710) .\end{array}$ \\
\hline $161 \mathrm{kV}$ Multi-point connection & 1 overloaded line (the branch connecting Fusing H-5855 and Han Bao H-5817). \\
\hline $345 \mathrm{kV}$ Single-point Connection & No overloaded line \\
\hline
\end{tabular}

\subsection{Analysis on the maximum three-phase short-circuit current}

The main purpose of analyzing fault current is to examine whether the interrupting capacity of circuit breakers in the system is enough to interrupt the maximum fault current. According to the Taipower interconnection rules, the maximum short-circuit currents for the $345 \mathrm{kV}$ and $161 \mathrm{kV}$ systems are respectively $63 \mathrm{kA}$ and $50 \mathrm{kA}$. Table 2 lists the simulation results: in the scenario of $345 \mathrm{kV}$ single-point connection, the entire wind farm is connected through the Zhang-Bin bus; thus the increase in shortcircuit current in this scenario is accordingly greater than those in other scenarios. If the Xien Xi bus and Han Bao bus occur grid faults, an obvious increase in short-circuit current can be observed in the multiple-point connection since a circuit loop is formed inside the wind farm between the two buses. Though still under the cap of $50 \mathrm{kA}$ as stipulated in the Taipower standards, the results suggest the need 
to pay more attention to the values of breaking current in subsequently installed breakers in the scenario of $161 \mathrm{kV}$ multi-point connection method.

Table 2. Steady-state maximum three-phase short-circuit current simulation results

\begin{tabular}{ccc}
\hline Location of Short-Circuit Bus & Connection Method & Maximum Three-Phase Short-Circuit Current (kA) \\
\hline \multirow{4}{*}{ Zhang Bin H-2300 } & $161 \mathrm{kV}$ Single Connection & 45.9792 \\
\cline { 2 - 3 } & $161 \mathrm{kV}$ Separate Connection & 45.9672 \\
\cline { 2 - 3 } & $161 \mathrm{kV}$ Multi-connection & 45.9801 \\
\cline { 2 - 3 } & $345 \mathrm{kV}$ Single Connection & 47.0824 \\
\hline \multirow{5}{*}{ Xien Xi H-5801 } & $161 \mathrm{kV}$ Single Connection & 43.2481 \\
\cline { 2 - 3 } & $161 \mathrm{kV}$ Separate Connection & 42.4877 \\
\cline { 2 - 3 } & $161 \mathrm{kV}$ Multi-connection & 44.9412 \\
\hline \multirow{3}{*}{ Han Bao H-5817 } & $161 \mathrm{kV}$ Single Connection & 40.2641 \\
\cline { 2 - 3 } & $161 \mathrm{kV}$ Separate Connection & 24.0258 \\
\cline { 2 - 3 } & $161 \mathrm{kV}$ Multi-connection & 25.3750 \\
\cline { 2 - 3 } & $345 \mathrm{kV}$ Single Connection & 39.9804 \\
\hline
\end{tabular}

Note: Prior to the wind farm connection, the maximum three-phase short-circuit currents read respectively $45.3092 \mathrm{kA}$, $39.9723 \mathrm{kA}$, and 23.4906 kA for Zhang Bin, Xien Xi, and Han Bao buses.

\section{Dynamic Analysis}

This section examines the transient stability of the Taipower $345 \mathrm{kV}$ bus when the system experiences grid faults, assuming that the wind farm operates at the rated and fixed wind speed for full-load power generation. It is further assumed that the wind farm operates with a controlled power factor of 1.0, and three-phase short-circuit faults take place in the $345 \mathrm{kV}$ Zhang Bin E-2300 bus. The fault is cleared after 6 cycles. Under the above simulation scenario, this study proceeds to analyze the frequency and voltage responses on the Xien Xi bus. The simulation results during off-peak hours are summarized in Tables 3 and 4. Taking the Xien Xi bus as an example, in the scenario of $161 \mathrm{kV}$ single-point connection, since the wind farm is connected to the Xien Xi bus, the wind farm is able to perform direct regulation at this connection point. The voltage drop at Xien Xi bus is therefore less drastic than those in other connection scenarios. Frequency, on the other hand, is under greater influence in the single-point connection; the range of frequency swing at the Xien Xi bus is accordingly greater than those in other connection scenarios.

Table 3. Simulation Results -Transient Voltage Stability at Xien Xi Bus

\begin{tabular}{lc}
\hline Connection Method & Voltage drop between initial and lowest voltages \\
\hline $161 \mathrm{kV}$ Single Connection & $0.9201 \mathrm{pu}$ \\
\hline $161 \mathrm{kV}$ Separate Connection & $0.9284 \mathrm{pu}$ \\
\hline $161 \mathrm{kV}$ Multi-connection & $0.9297 \mathrm{pu}$ \\
\hline $345 \mathrm{kV}$ Single Connection & $0.9284 \mathrm{pu}$ \\
\hline
\end{tabular}

Table 4. Simulation Results -Transient Frequency Stability at Xien Xi Bus

\begin{tabular}{lc}
\hline Connection Method & Range of Frequency Swing \\
\hline $161 \mathrm{kV}$ Single Connection & $59.7902 \sim 60.8114 \mathrm{~Hz}$ \\
\hline $161 \mathrm{kV}$ Separate Connection & $59.7903 \sim 60.6659 \mathrm{~Hz}$ \\
\hline $161 \mathrm{kV}$ Multi-connection & $59.7904 \sim 60.6437 \mathrm{~Hz}$ \\
\hline $345 \mathrm{kV}$ Single Connection & $59.7937 \sim 60.1199 \mathrm{~Hz}$ \\
\hline
\end{tabular}




\section{Analysis on the Critical Clearing Time (CCT)}

Different from those in other countries and regions, the power system in Taiwan is an isolated one characterized by a high density and a north-south longitudinal direction. Though Taipower has built three north-south extra high-voltage power transmission lines, major accidents may still cause problems in transmission stability. This section accordingly focuses on the system's critical clearing time, a key index of transient stability, examining whether the system is able to sustain balance and normal operation after experiencing grid faults and using the result as a yardstick to measure the increase or decrease in critical clearing time. According to the Taipower regular practice of unit dispatch during off-peak hours, in order to avoid load shedding of low-cost generators and the limit by the minimum operating time of some generators, the Taipower' s pumped storage power plants in Mingtan and Daguan play a crucial role in load shedding. As a result, there exists a greater difference in the rotor angle between the generators in South Taiwan and in North Taiwan, making transient stability a more serious problem during off-speak operation. Based on the Taipower system planning experience, when any new generator is installed, system transient stability at off-peak operation must be evaluated. If the system's transient stability meets the required standards, there will be no problem either during peak operation.

Assuming that the wind farm operates at the rated and fixed wind speed for full-load power generation, this section examines the impacts of the wind farm's connection to the power system on the critical clearing time in different connection scenarios. In this study, it is assumed that the Zhang Bin bus appears grid fault and then one of the lines between H-2300 bus and E-540 bus in Zhang Bin area trips offline.

According to a previous study [9], the critical clearing time of a power system could be directly related to the volume and direction of power transmission and the grid topology. The greater the volume of transmitted power, the longer the critical clearing time. Additionally, different connection scenarios would result in different volume and direction of power transmission. Simulation results on CCT are summarized in Table 5, which indicates the CCT in all connection scenarios is twice longer than the CCT requirement in Taipower standard. Compared to the system without the offshore wind farm, the $161 \mathrm{kV}$ single-point connection with the wind farm has an increase in critical clearing time while the $161 \mathrm{kV}$ multi-point connection facilitates a decrease in critical clearing time.

Table 5. Critical Clearing Time during off-peak hours

\begin{tabular}{lc}
\hline Connection Method & Critical Clearing Time (Cycle) \\
\hline Wind Farm has not connected yet & 12.3672 \\
\hline 161 kV Single-point Connection & 12.4688 \\
\hline 161 kV Separate-point Connection & 12.4219 \\
\hline 161 kV Multi-point connection & 12.2891 \\
\hline 345 kV Single-point Connection & 12.3672 \\
\hline
\end{tabular}

\section{Conclusions}

The study focuses on the connection of the Zhanghua Offshore Wind Farm (with a scheduled capacity of $864 \mathrm{MW}$ ) into the Taipower system to perform various steady- and dynamic-state simulations and analyses. Major issues under examination include power flow, fault current, system transient stability, and critical clearing time. Impacts of these issues on the power system under different connection scenarios are simulated and analyzed.

In steady-state analyses, the $345 \mathrm{kV}$ single-point connection demonstrates a better performance because all existing transmission lines are not overloaded after the connection of the wind farm. In addition, based on our results, the wind farm is capable of bringing more short-circuit current when the system appears faults. The value of fault current would be determined by the connection location of the wind farm. In dynamic analyses, when grid faults take place, the $161 \mathrm{kV}$ single-point connection reports a smaller voltage drop but a greater range of frequency swing than the other three connection scenarios. In terms of 
critical clearing time, all simulation results appear to be over twice longer than the requirement of the Taipower standard.

In future development of large-scale offshore wind farms, the above simulation results can be expected to provide Taiwan power system with valuable reference for selecting the proper method of connecting a wind farm to the power system so as to reduce the system steady- and dynamic-state impacts.

\section{References}

[1] Eriksen PB. System operation with high wind penetration. IEEE Power and Energy Magazine, 2005; 3(6):65-74.

[2] Huertas-Hernando D. Analysis of grid alternatives for North Sea offshore wind farms using a flow-based market model. In: Proc. of the 7th International Conference on Energy Market, 2010:1-6.

[3] Bresesti P, Kling WL, Vailati R. Transmission expansion issues for offshore wind farms integration in Europe. Presented at: IEEE/PES Transmission and Distribution Conference and Exposition, 2008

[4] Gautam D. Impact of increased penetration of DFIG-based wind turbine generators on transient and small signal stability of power systems. IEEE Transactions on Power Systems, 2009; 24(3):1426-1434.

[5] El-Fouly. Impact of wind generation control strategies, penetration level and installation location on electricity market prices. IET Renewable Power Generation, 2008; 2(3):162-169.

[6] Ullah NR. Voltage and transient stability support by wind farms complying with the E.ON Netz grid code. IEEE Transactions on Power Systems, 2007; 22(4):1647-1656.

[7] Gertmar L. Wind energy powers-that-be successor generation in globalization. IEEE Transaction on Energy Conversion, 2007; 22(1):13-28.

[8] Technical Rules of Renewable Energy Generation Connected to Taipower Transmission and Distribution Systems, 2011

[9] Yorino N, Priyadi A, Kakui H, Takeshita M. A new method for obtaining critical clearing time for transient stability. IEEE Transactions on Power Systems, 2010; 25(3):1620-1626. 